This is the peer reviewed version of the following article: Steinbauer, M. J., Field, R., Grytnes, J.-A., Trigas, P., Ah-Peng, C., Attorre, F., Birks, H. J. B., Borges, P. A. V., Cardoso, P., Chou, C.-H., De Sanctis, M., de Sequeira, M. M., Duarte, M. C., Elias, R. B., Fernández-Palacios, J. M., Gabriel, R., Gereau, R. E., Gillespie, R. G., Greimler, J., Harter, D. E. V., Huang, T.-J., Irl, S. D. H., Jeanmonod, D., Jentsch, A., Jump, A. S., Kueffer, C., Nogué, S., Otto, R., Price, J., Romeiras, M. M., Strasberg, D., Stuessy, T., Svenning, J.-C., Vetaas, O. R. and Beierkuhnlein, C. (2016), Topography-driven isolation, speciation and a global increase of endemism with elevation. Global Ecol. Biogeogr., 25: 10971107, which has been published in final form at https://doi.org/10.1111/geb.12469. This article may be used for non-commercial purposes in accordance With Wiley Terms and Conditions for self-archiving. 


\section{Topography-driven isolation, speciation and a global increase of endemism with elevation}

Manuel J. Steinbauer ${ }^{1,2}$, Richard Field ${ }^{3}$, John-Arvid Grytnes ${ }^{4}$, Panayiotis Trigas $^{5}$, Claudine Ah-Peng ${ }^{6}$, Fabio Attorre ${ }^{7}$, H. John B. Birks ${ }^{4,8}$ Paulo A.V. Borges ${ }^{9}$, Pedro Cardoso ${ }^{9,10}$, Chang-Hung Chou ${ }^{11}$, Michele De Sanctis $^{7}$, Miguel M. de Sequeira ${ }^{12}$, Maria C. Duarte ${ }^{13,14}$, Rui B. Elias ${ }^{9}$, José María Fernández-Palacios $^{15}$, Rosalina Gabriel ${ }^{9}$, Roy E. Gereau ${ }^{16}$, Rosemary G. Gillespie ${ }^{17}$, Josef Greimler ${ }^{18}$, David E.V. Harter ${ }^{1}$, Tsurng-Juhn Huang ${ }^{11}$, Severin D.H. Irl ${ }^{1}$, Daniel Jeanmonod ${ }^{19}$, Anke Jentsch ${ }^{20}$, Alistair S. Jump ${ }^{21}$, Christoph Kueffer ${ }^{22}$, Sandra Nogué ${ }^{23,4}$, Rüdiger Otto ${ }^{15}$, Jonathan Price ${ }^{24}$, Maria M. Romeiras $^{14,25}$, Dominique Strasberg ${ }^{6}$, Tod Stuessy ${ }^{26}$, Jens-Christian Svenning ${ }^{2}$, Ole R. Vetaas ${ }^{27}$, Carl Beierkuhnlein $^{1}$

${ }^{1}$ Department of Biogeography, BayCEER, University of Bayreuth, D-95440 Bayreuth, Germany

${ }^{2}$ Section for Ecoinformatics \& Biodiversity, Department of Bioscience, Aarhus University, 8000 Aarhus, Denmark

${ }^{3}$ School of Geography, University of Nottingham, University Park, NG7 2RD, UK

${ }^{4}$ Ecological\& Environmental Change Research Group, Department of Biology, University of Bergen, PO Box 7803, N-5020 Bergen, Norway

${ }^{5}$ Laboratory of Systematic Botany, Department of Crop Science, Agricultural University of Athens, Iera Odos 75, 11855, Athens, Greece

${ }^{6}$ Université de La Réunion, UMR PVBMT, 15 Avenue René Cassin, CS 92003, 97744, Saint-Denis, Cedex, France

${ }^{7}$ Department of Environmental Biology, University Sapienza of Rome, I-00185, Rome, Italy

${ }^{8}$ Environmental Change Research Centre, University College London, London, WC1E 6BT, UK

${ }^{9}$ Centre for Ecology, Evolution and Environmental Changes (Ce3C) and Azorean Biodiversity Group, Universidade dos Açores, Rua Capitão Joãod'Ávila, sn 9700-042 Angra do Heroísmo, Terceira, Açores, Portugal

${ }^{10}$ Finnish Museum of Natural History, University of Helsinki, POBox 17, 00014 Helsinki, Finland

${ }^{11}$ Research Centre for Biodiversity, China Medical Univ., Taichung, Taiwan 40402, Republic of China

${ }^{12}$ GBM, Universidade da Madeira, Centro de Ciências da Vida, Campus da Penteada, 9000-390, Funchal, Portugal

${ }^{13}$ Tropical Research Institute, Travessa Conde da Ribeira 9, Lisbon, Portugal

${ }^{14}$ Centre for Ecology, Evolution and Environmental Changes (Ce3C), Faculty of Sciences, University of Lisbon, Campo Grande, Portugal

${ }^{15}$ Island Ecology and Biogeography Research Group. Instituto Universitario de Enfermedades Tropicales y Salud Pública de Canarias (IUETSPC), Universidad de La Laguna, Tenerife, Canary Islands 38206, Spain.

${ }^{16}$ Missouri Botanical Garden, P.O. Box 299, St. Louis, Missouri,63166-0299, USA

${ }^{17}$ Environmental Science, University of California Berkeley, 130 Mulford Hall, Berkeley, CA 947203114

${ }^{18}$ Department of Botany and Biodiversity Research, University of Vienna, Rennweg 14, A-1030, Vienna, Austria

${ }^{19}$ Laboratoire de systématique végétale et biodiversité, Université de Genève et Conservatoire et Jardin botaniques de la Ville de Genève, case postale 60, 1292 Chambésy, Suisse.

${ }^{20}$ Department of Disturbance Ecology, BayCEER, University of Bayreuth, DE-95447 Bayreuth, Germany

${ }^{21}$ Biological and Environmental Sciences, School of Natural Sciences, Univ. of Stirling, Stirling, FK9 $4 L A, U K$

${ }^{22}$ Institute of Integrative Biology, Universitätsstrasse 16, ETH Zentrum, CHN, CH-8092 Zürich, Switzerland 
${ }^{23}$ Oxford Long-term Ecology Lab, Biodiversity Institute, Department of Zoology, University of Oxford, OXI 3PS, Oxford, UK

${ }^{24}$ Department of Geography and Environmental Studies, University of Hawai'i at Hilo $200 \mathrm{~W}$. Kawili St., Hilo, HI 96720-4091

${ }^{25}$ University of Lisbon, Faculty of Science, Biosystems and Integrative Sciences Institute (BioISI), Campo Grande 1749-016 Lisbon, Portugal

${ }^{26}$ Herbarium, Museum of Biological Diversity, The Ohio State University, 1315 Kinnear Road, Columbus, Ohio 43212, USA

${ }^{27}$ Department of Geography, University of Bergen, PB 7802, N-5020 Bergen, Norway

Keywords: altitude, biogeographic processes, diversity, ecological mechanisms, endemism, global relationship, isolation, latitudinal gradient, mixed-effects models, sky islands

Corresponding author: Manuel Steinbauer, Department of Biogeography, BayCEER, University of Bayreuth, D-95440 Bayreuth, Germany, Phone: +49921552211, Manuel.Steinbauer@uni-bayreuth.de

\begin{abstract}
Aim: Higher-elevation areas on islands and continental mountains tend to be separated by longer distances, predicting higher endemism at higher elevations; our study is the first to test the generality of the predicted pattern. We also compare it empirically with contrasting expectations from hypotheses invoking higher speciation with area, temperature and species richness.

Location: 32 insular and 18 continental elevational gradients from around the world.

Methods: We compiled entire floras with elevation-specific occurrence information, and calculated the proportion of native species that are endemic ('percent endemism') in $100 \mathrm{~m}$ bands, for each of the 50 elevational gradients. Using generalized linear models, we tested the relationships between percent endemism and elevation, isolation, temperature, area and species richness.

Results: Percent endemism consistently increased monotonically with elevation, globally. This was independent of richness-elevation relationships, which had varying shapes but decreased with elevation at high elevations. The endemism-elevation relationships were consistent with isolationrelated predictions, but inconsistent with hypotheses related to area, richness and temperature.

Main conclusions: Higher per-species speciation rates caused by increasing isolation with elevation are the most plausible and parsimonious explanation for the globally consistent pattern of higher endemism at higher elevations that we identify. We suggest that topography-driven isolation increases speciation rates in mountainous areas, across all elevations, and increasingly towards the equator. If so, it represents a mechanism that may contribute to generating latitudinal diversity gradients in a way that is consistent with both present-day and palaeontological evidence.
\end{abstract}




\section{Introduction}

Globally pervasive and repeated geographic biodiversity patterns such as latitudinal and elevational diversity gradients are strongly affected by the evolution of species (Wallace, 1880; Rohde, 1992; Allen \& Gillooly, 2006; Mittelbach et al., 2007). Indeed, these patterns must result from gains and losses of species over time, and speciation is one key type of gain (the other being immigration). Therefore various hypotheses have been advanced to explain spatial variation in speciation rates that operate through distinct mechanisms and are not necessarily mutually exclusive. One prominent explanation, favoured by Rohde (1992), and more recently by Brown (2014) and others as part of the 'metabolic theory of ecology', proposes that speciation rate increases with temperature (hypothesis 1). This would cause higher rates of speciation in lower latitudes and at lower elevations. Another popular potential mechanism is that more intense biotic interactions promote speciation, including the 'diversity begets diversity' hypothesis (hypothesis 2; Van Valen, 1973; Rohde, 1992; Gillooly et al., 2004; Emerson \& Kolm, 2005). As a consequence, species-rich systems with intense species interactions would show higher rates of speciation. Larger areas are also thought to promote speciation (hypothesis 3; Losos \& Schluter, 2000), including the increasing chance of allopatric divergence (Kisel \& Barraclough, 2010). All these mechanisms predict higher speciation rate per species and increased addition to overall species numbers within a specified area (i.e. speciation rate per area).

Elevational gradients provide unique opportunities for testing hypotheses deduced from models and theories advanced to explain diversity gradients (McCain \& Sanders, 2010; Hutter et al., 2013). The leading theories outlined above, which seek to (partly) explain species richness gradients via equivalent gradients of speciation, are typically associated with latitudinal gradients, but are not specific to them, and the mechanisms they invoke should also apply at the smaller geographic extents of elevational gradients. All of them predict either negative or hump-shaped relationships between elevation and speciation rate because lower elevations are warmer, the area occupied by altitudinal belts tends to be larger at lower elevations and low to mid elevations tend to have more species (Rahbek, 1995; McCain, 2005). According to all these theories, the proportion of native species originating from local speciation should be lowest at high elevations - assuming, as do those theories, that extinction is not systematically lower at high elevation.

Another speciation driver is isolation (Coyne \& Orr, 2004). Isolation by sea, for example, is thought to be integral to explaining speciation on islands. This factor is reflected in the large number of endemic island species, which disproportionally contribute to the global species pool (Kreft et al., 2008). More generally, the promotion of speciation by gene-flow barriers is widely known (Coyne \& Orr, 2004). The barriers may include geographic distance or specific features such as sea separating terrestrial systems or land separating marine systems, depending on the organisms concerned. They may also include topographic features such as mountain ranges dividing low-elevation systems or major valleys dividing high-elevation systems. Indeed, Gillespie \& Roderick (2014) found that the chance of population isolation increases in more topographically diverse areas because of gene-flow barriers. Allopatric speciation is therefore usually cited to explain specific species richness patterns involving particular barriers, or to explain island biogeographic (e.g. Whittaker \& Fernández-Palacios, 2007) or regional (e.g. Qian \& Ricklefs, 2000) diversity patterns - but not previously considered to vary systematically enough to account for global-scale biodiversity gradients such as elevational or latitudinal ones (Mittelbach et al., 2007). Thus, isolation is not a prominent mechanism invoked in attempts to explain grand clines in biodiversity, and there are few studies examining effects of isolation at a global scale.

Geographical isolation tends to increase with elevation whether or not mountains resemble the conical shape of many volcanic islands (Elsen \& Tingler, 2015). It has been known since von Humboldt \& Bonpland (1807) that most species are confined to fairly specific zones within an elevational gradient; the mechanism may be that upward movement is restricted mainly by physiological tolerance and downward movement mainly by competition (Ghalambor et al., 2006). This confinement to particular elevational zones creates isolation, even in the absence of a clear feature acting as a barrier. In particular, for non-lowland species, the geographical extent of inhospitable lower-elevation terrain separating suitable habitat (which may or may not also include water) increases with elevation (Fig. 1; Steinbauer et al., 2013). Although the distinction is partly a matter of degree, we use the term 'topographic isolation' to refer to isolation by a specific feature that 
acts as a distinct barrier and 'elevational isolation' to refer to the isolation caused by elevational difference. We use 'topography-driven isolation' to refer to a combination of the two.

If isolation is an important driver of speciation (by reducing gene flow), elevation-driven isolation should result in repeated patterns of increasing speciation with elevation (hypothesis 4). There is indeed support from phylogenetic studies for an increase in diversification with elevation (Hutter et al., 2013; Merckx et al., 2015) particularly in high-elevation "island-like habitats" (Hughes \& Eastwood 2006). Phylogenetic evidence indicates that many high-elevation endemics across the globe are phylogenetically young taxa resulting from recent fast diversification (e.g. New Zealand Alps, Winkworth et al., 2004; the Andes, Hutter et al., 2013; or on South American Tepuis, Salerno et al., 2012; East Malaysia, Merckx et al., 2015). Although speciation and endemism are not automatically linked, trends in endemism should broadly reflect gradients of speciation. Some studies report consistent increases in per-species levels of endemism with elevation in localized areas (e.g. Kessler, 2002; Vetaas \& Grytnes, 2002; Mallet-Rodrigues et al., 2010; Jump et al., 2012; Nogué et al., 2013, Irl et al., 2015), but no global synthesis has yet been attempted.

The reasoning on elevation-driven isolation implies that elevational zones effectively act as islands that become smaller and more remote with increasing elevation. The concept of mountain-tops as islands is not new (e.g. Mayr \& Diamond, 1976), but it is less common to conceptualise the island biogeography of elevational zones as a continuous gradient. Thus, higher-elevation zones are more isolated from each other, less connected and have smaller extent than lower-elevation zones. Following the concepts of island biogeography, and given sufficient elevational range, higher elevations should therefore be expected to be (1) decreasingly species rich but (2) contain increasingly high proportions of endemics, assuming sufficient time for speciation (Fig. 1). The first prediction is in line with the leading hypotheses outlined above that invoke the mechanisms of increased speciation with temperature, area and biodiversity. The second prediction of higher per-species endemism at higher elevations, however, contrasts with the higher per-species endemism at low to mid-elevations predicted by those other hypotheses. While the mechanisms underlying these hypotheses are not mutually exclusive, the opposing predictions allow a comparative test of the importance of isolation for speciation in a global context.

Here we use 50 elevational gradients from around the world, covering entire plant floras, to evaluate the global relationship between the proportion of native species that are endemic (hereafter 'percent endemism') and elevation. We focus on elevational gradients on islands, where speciation can be most reliably inferred from endemism. We also test whether the relationship between endemism and elevation applies to continental mountains, where elevational isolation is present but the additional isolation by sea does not apply. Using our island data, we test the predictions from the four hypotheses that percent endemism should be positively related to each of (1) temperature, (2) species richness, (3) area and (4) isolation.

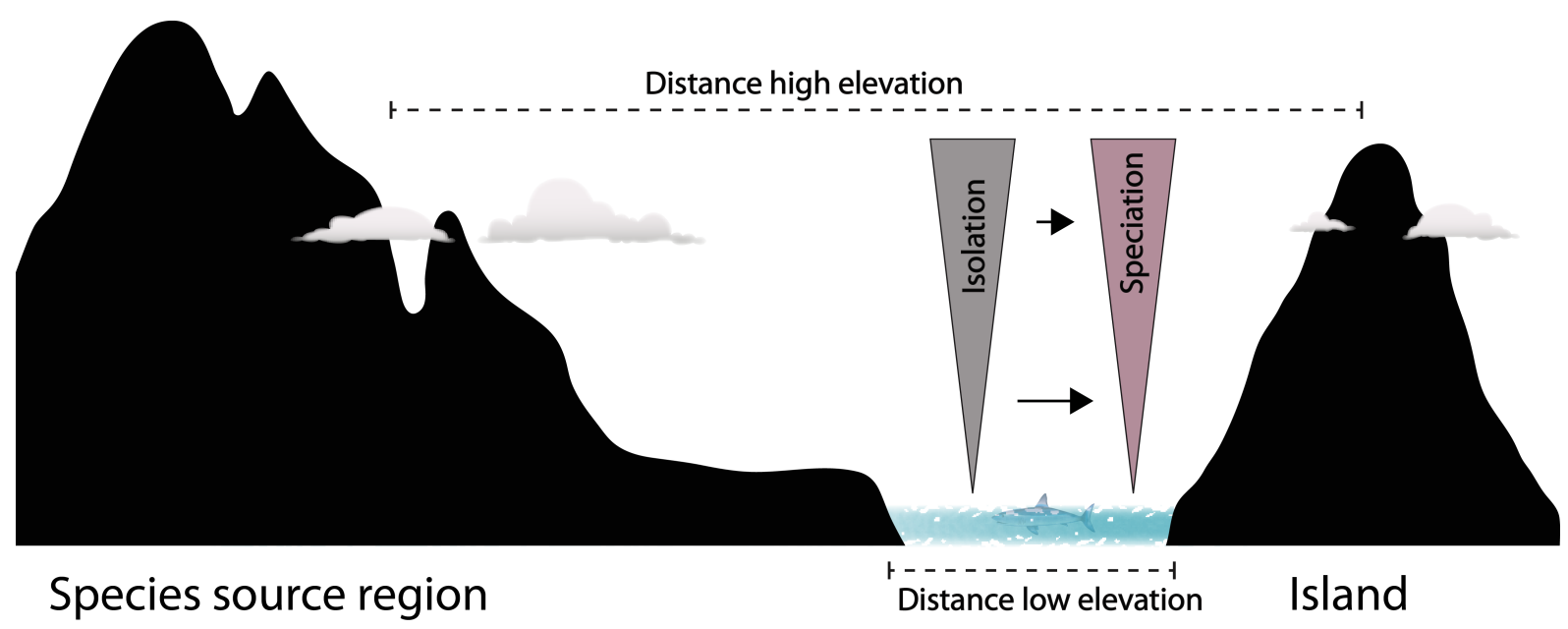

Figure 1: On islands or mountains, high elevation ecosystems are more isolated than low-elevation ecosystems. This is because potential source regions for colonizing species (or individuals) are further away (geographic isolation) and smaller (target area effect) than low-elevation ecosystems. Greater isolation should be reflected in a higher speciation rate. 


\section{Methods}

We assembled complete native floras for 32 high-elevation islands and 18 continental mountain systems, with maximum elevation reaching up to $4200 \mathrm{~m}$ for islands and $6000 \mathrm{~m}$ for continents, drawn from all major oceans and continents except Antarctica (Table S1, and Appendix 1 - Data Sources). Key selection criteria were (1) a long elevational gradient (preferably more than $1000 \mathrm{~m}$, but occasionally slightly less), (2) enough endemic species (definition below) for the response variable (percent endemism) to contain sufficient variance to model with confidence, (3) good coverage of the flora and (4) reliable presence-absence data along the elevational gradient for all the species. All datasets we accessed that satisfied these criteria were included. However, criteria 1 and (particularly) 2 resulted in no datasets poleward of $54^{\circ}$ (Tierra del Fuego): at high latitudes there are typically very few species that qualify as 'endemic' using our criterion (see below). We focused on vascular plant species (though $28 \%$ of the datasets were only for seed plants and the Peru Andes only include woody species) because it is for this taxon that spatially explicit data are most available. Because we aimed to identify general patterns, we performed parallel analyses (which showed strikingly similar results; Figure S1) for arthropod data from six Azorean islands for which high-quality, spatially explicit data were available (Borges et al., 2010).

Native species richness and endemic species richness were calculated for $100 \mathrm{~m}$ elevational belts. Endemic species were defined as species native only to the archipelago (defined as the focal island in cases where it is closer to a continent than to another island, e.g. Cyprus) or mountain range.

The response variable was the percentage of native species that are endemic (percent endemism), the best available proxy for per-species speciation rates (Steinbauer et al., 2013). The use of percentage values also has the major advantage over richness-based indices that the values are independent of environment-richness and area-richness relationships, which tend to override other patterns in biogeography (thus in our datasets there is no consistent relationship between elevation and endemic species richness). Further, this method is relatively robust to sampling biases (Steinbauer et al., 2013).

Since percentages based on few species are unreliable, we excluded elevational belts with fewer than 10 native species. We assessed the reliability of the percent endemism values using bootstrapping: we drew species from the pool of all natives (endemic and non-endemic) in each $100 \mathrm{~m}$ elevational belt, with replacement, until we reached the total observed species richness. This was done 1000 times for each data point, the central $95 \%$ (i.e. between the $2.5 \%$ and $97.5 \%$ quantiles) of the resulting percent endemism values providing the confidence envelope. Most analyses used generalized linear models with binomial errors and a logit link, and parallel ordinary least-squares regressions for comparison. Mixed-effects modelling with binomial errors and logit link was used to assess the global relationship between percent endemism and elevation, with island vs. continental mountain included as a random effect, and was performed using $\mathrm{R}$ package lme 4 version 1.1-7 in $\mathrm{R}$ version 3.2.0.

Temperature, area and isolation were quantified as follows, for islands only. A global digital elevation model with $30 \mathrm{~m}$ resolution (ASTER GDEM, a product of METI and NASA) was used to slice all investigated islands into $100 \mathrm{~m}$ elevational bands, resulting in 560 bands in total. Resolution was resampled to $60 \mathrm{~m}$ for Tasmania and Taiwan to meet computational limits. Mean annual temperature from $1 \mathrm{~km}$ resolution WorldClim data was downscaled using the ASTER GDEM and an elevational lapse rate of $0.6^{\circ} \mathrm{C} / 100 \mathrm{~m}$. Area and mean temperature of each elevational band were calculated. Isolation was quantified using an established approach (Weigelt \& Kreft, 2013): 'distance to a climatically similar landmass'. This was approximated as the distance of the elevational band to the nearest terrestrial area outside the archipelago that has a similar (within $1{ }^{\circ} \mathrm{C}$ ) mean annual temperature. To match our definition of endemism (archipelago endemics), all other islands belonging to the same archipelago as the focal elevational belt were removed before quantifying isolation. Our measure of climatic similarity does not include precipitation because precipitation interpolations for islands from global data are highly problematic. The Juan Fernández Islands (Robinson Crusoe and Alejandro Selkirk) were excluded from this analysis because of missing WorldClim data, and Corsica was excluded because the elevational species distribution resolution is too coarse for $100 \mathrm{~m}$ bands. Processing of spatial data was done using R packages raster version 2.3-40, maptools version 0.8-36 and rgeos version 0.3-8.

In order to test the predictions from the four hypotheses 1) area, 2) temperature, 3) isolation and 4) species richness of each elevational band were directly related to percent endemism across all 
the islands in our dataset. First, we correlated percent endemism with the four predictors separately. Variation accounted for by predictors was quantified using McFadden's pseudo- $R^{2}$ (1-(log likelihood of the full model/log likelihood of the null model)). We log-transformed area, richness and isolation because this improved residuals and model performance. Secondly, we combined the four predictors in one model and used plots of partial residuals to visualise the modelled effects. Finally, we rebuilt this multiple model using standardized predictor variables and used the model coefficients to indicate relative importance.

\section{Results}

The plant floras of the 32 high-elevation insular and 18 continental mountain systems compiled for this study differed considerably in overall species richness (range 75-3186, mean 776 for islands; range 127-8067, mean 1454 for continental mountains) and overall percent endemism (range 3-80\%, mean $41 \%$ for islands; range $3-72 \%$, mean $33 \%$ for continental mountains). The dataset we analysed comprised 51,009 species records with specific elevational occurrence information. The peak of Robinson Crusoe Island $(915 \mathrm{~m})$ was the elevational band with the highest percent endemism $(96 \%)$.

We found a globally consistent and highly significant pattern of monotonic increase in percent endemism with increased elevation (Fig. 2). We found this when analysing island systems, continental mountain systems, or both combined $(P<0.001$ in all cases). The pattern was independent of underlying richness-elevation gradients, which had differing shapes but consistently decreased with elevation at high elevations (Fig. S2). In most cases, percent endemism more than doubled from the lowest to the highest elevations, in some cases increasing more than tenfold. Assessed individually, 28 of the 32 island relationships and all 18 of the continental mountain relationships were significantly positive $(P<0.001$ for all except Pico in Azores, where $P<0.05$ ). The other four (Alejandro Selkirk, La Gomera, El Hierro, Tierra del Fuego) had no significant relationship between percent endemism and elevation.

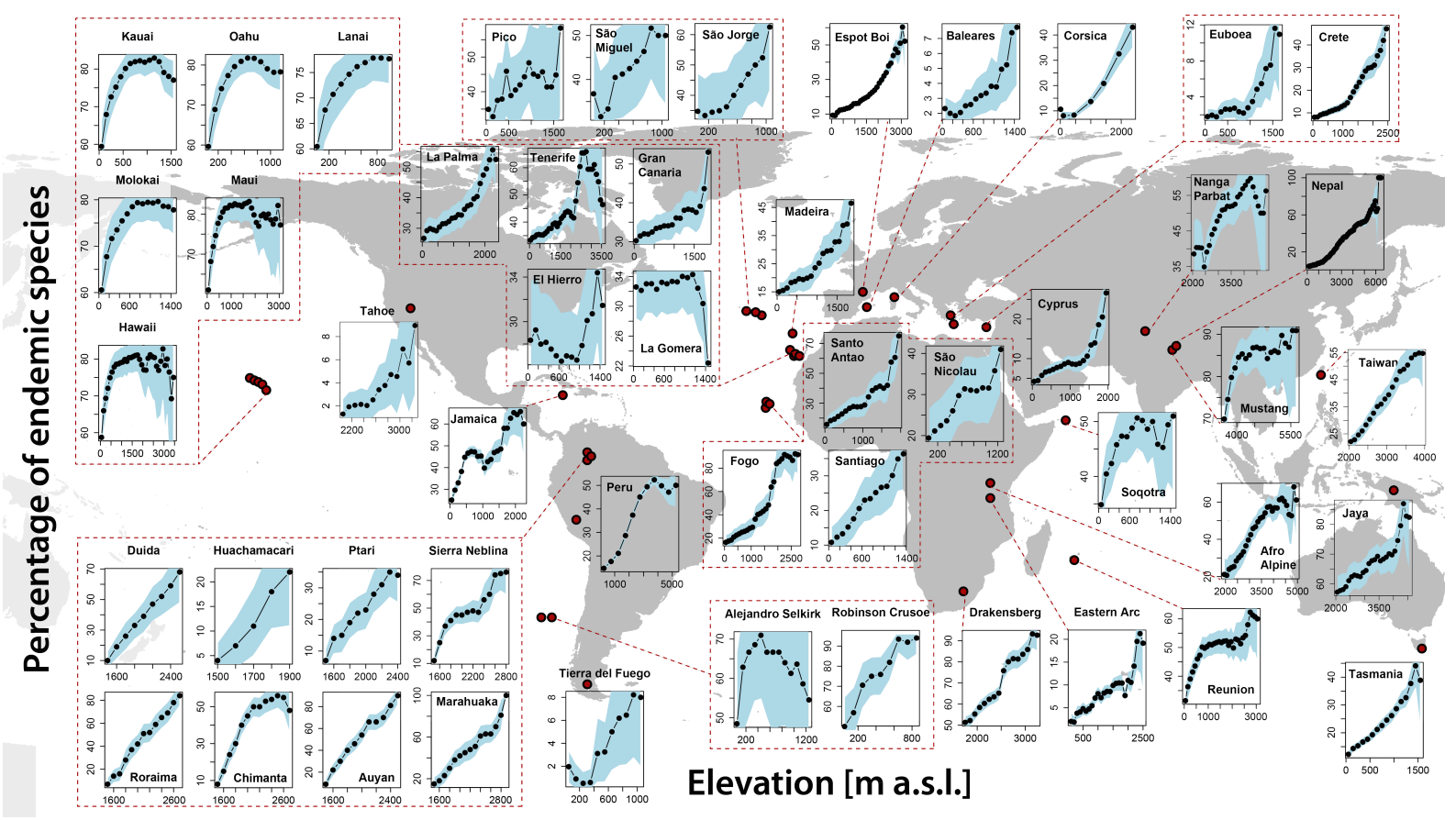

Figure 2: Elevation-percent endemism relationships globally. Vertical axes show the percentage of native species that are endemic (note the varying scales); horizontal axes show elevation in $100 \mathrm{~m}$ bands. Blue shading indicates $95 \%$ envelopes from bootstrap resampling (see Methods summary). Graphs surrounded by dashed boxes belong to the same archipelago or region. Assessed individually using generalized linear models (binomial), 28 of the 32 island and all of the 18 continental mountain relationships are significantly positive $(\mathrm{P}<0.001$ for all except Pico, where $\mathrm{P}<0.05)$. The other four (Alejandro Selkirk, La Gomera, El Hierro, Tierra del Fuego) were non-significant. 
Isolation had by far the greatest explanatory power of the four predictor variables in our hypothesis testing. Analysed individually, its pseudo- $r^{2}$ was $0.78(P<0.001)$. The relationship was positive (increased percent endemism with isolation), as predicted by the isolation hypothesis. Species richness (pseudo- $r^{2}=0.23$ ), area (pseudo- $r^{2}=0.15$ ) and temperature (pseudo- $r^{2}=0.04$ ) were all negatively correlated with percent endemism, significantly so $(P<0.001$ for all), opposing the predictions of the related hypotheses (metabolic theory of ecology, speciation-area relationship, diversity begets diversity). Using ordinary least-squares regression, the results were qualitatively identical, but the $r^{2}$ for isolation was slightly lower (0.71). Including all four predictors in one multiple model reinforced the dominance of isolation (Fig. 3), and adding area, temperature and species richness only increased the ordinary least-squares $R^{2}$ to 0.74 (from 0.71 ), and the pseudo- $R^{2}$ actually decreased to 0.75 (from 0.78 ). In the multiple model, the effects of species richness and area were weakly positive (Fig. 3), unlike in the single regressions. The biggest residuals represented unexpectedly high percent endemism throughout Socotra, and on the peaks of Jamaica and Fogo (Cape Verde).
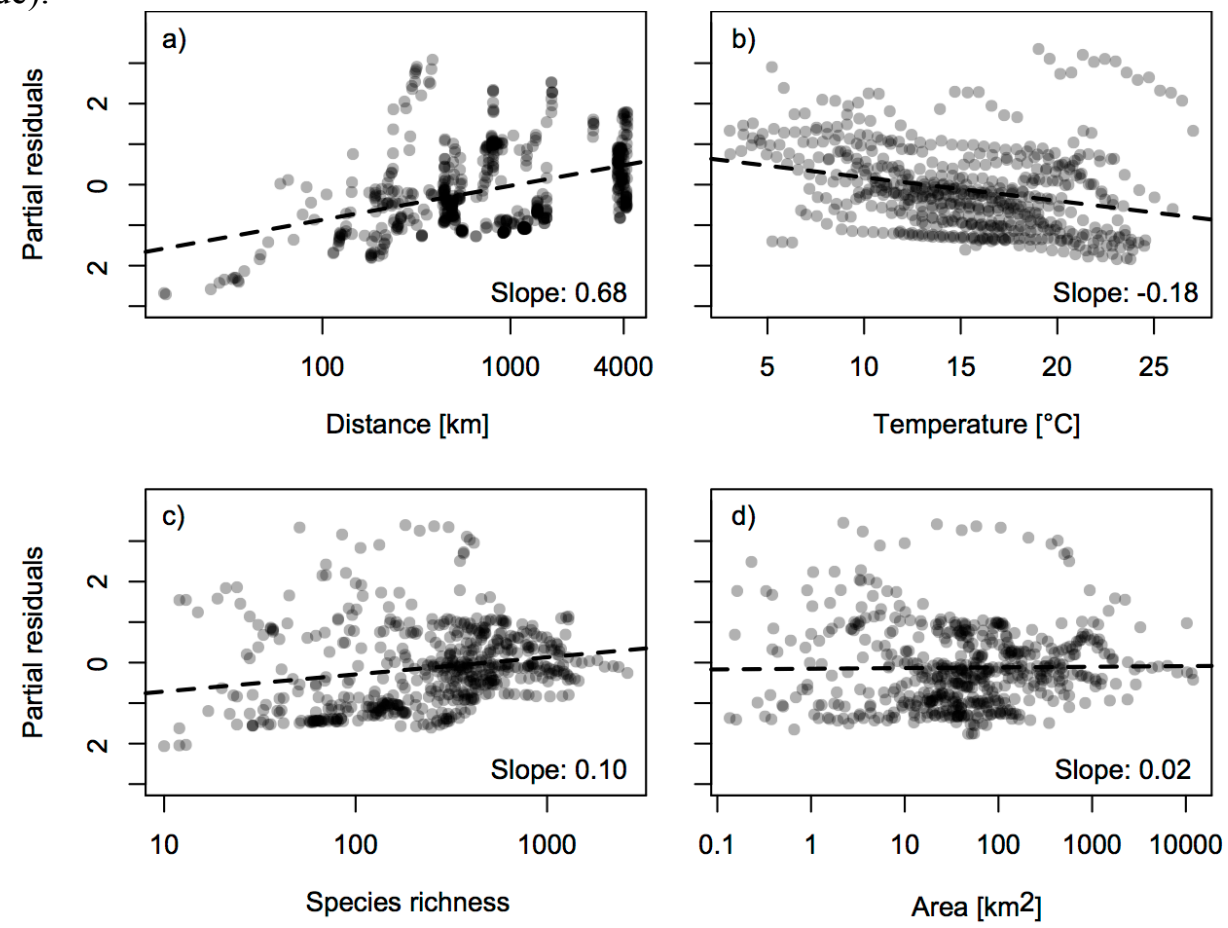

Figure 3: Partial residuals of the multiple generalized linear model accounting for percent endemism in elevational bands using area, temperature, species richness and isolation, plotted against each variable. Each panel shows the relationship between the variable and the residuals from a model excluding this variable, and including the other three. Panels are ordered in descending order of explanatory power of the predictor in the model. Points are semi-transparent to visualise the density of points on the graphs, so apparently darker points represent several points in the same place. 'Slope' indicates the slope coefficients from a generalised linear model (logit-link) with standardised variables (to support comparability).

\section{Discussion}

The monotonic increase in percent endemism with elevation, previously known from a range of case studies, is here documented globally for the first time, over long elevational gradients on continents and islands alike. The increase is remarkably globally consistent for a pattern measured in nature at fine grain and landscape extent, and much more consistent than the equivalent species richnesselevation gradients in the same data (Fig. S2). This consistency indicates that the relationship applies globally and implies that it is predictable. The different geological ages of the islands and continental mountains in our dataset suggest that the pattern may also be repeated through time. Relationships that are predictable in space and time can contribute to a general explanation of pervasive biodiversity patterns (Whittaker et al., 2001). Our results allow us to evaluate probable isolation effects against 
those of temperature, area and richness within our study system, and we find that these probable isolation effects are dominant. Our findings also allow us to contribute towards a general explanation for the anomalously high biodiversity of tropical and sub-tropical mountains, and in turn towards understanding latitudinal biodiversity gradients. We now expand on these points.

\section{Endemism, speciation rates and evaluation of the hypotheses}

For the long elevational gradients in our data, the patterns of percent endemism are consistent with the predictions of the isolation hypothesis, but not with those of the metabolic theory of biology, nor the area and diversity-begets-diversity hypotheses. Those predictions were made on the basis that percent endemism is a reasonable proxy for per-species speciation rate. But to what extent does the increase in percent endemism reflect increasing speciation rate with elevation? Speciation rate, as conceptualized in this manuscript, is the average time one species takes to diverge into two reproductively isolated species (e.g. Knope et al., 2012; see also Yule, 1924). The use of percent endemism to measure speciation rate involves the assumption that the large majority of endemic species on islands (or mountains) derives from in situ speciation. This assumption has considerable support, at least for oceanic islands (Stuessy et al., 2006), and we consider it reasonable to assume that most of the endemic species in our island data evolved within the archipelago (another key reason for using archipelago-level endemism). The fact that the same relationship between elevation and endemism is also found for continental mountains (Fig. 2) suggests that in situ speciation may also account for most of the endemics in our continental mountain data. This is consistent with phylogenetic studies showing increased diversification rate with elevation in continental mountains (Hutter et al., 2013; Merckx et al., 2015).

Percent endemism is likely to be affected also by extinction, and possibly by other circumstances (e.g. palaeoendemism, dispersal limitation of endemics and altitudinal differences in immigration rate; Steinbauer et al., 2012). The presence of elevational gradients reduces extinction risk caused by climatic changes as species can track their climatic niche by shifting over short spatial distances along strong climatic gradients (Sandel et al., 2011; Fjeldså et al., 2012). On high-elevation islands, extinction risk may be slightly higher towards the summit and at the coast were some species might meet their temperature range limits (McCain 2005). However, oceanic influences tend to cause more stable climates particularly in low elevations, likely mitigating climate induced extinctions there (Cronk, 1997). We thus expect extinction rates to mainly increase with elevation because of smaller areas and more variable climate; this would lead to decreasing percent endemism with elevation if temporal species turnover is faster than clado- and anagenetic evolutionary processes, but we found an increase. Higher extinction rates may enhance speciation opportunities for the remaining species. Also, historical land-use changes in lowlands may affect percent endemism there. However, our analyses are based only on native species (not aliens), and we consider it very unlikely that land use and other human influences affect endemic species so differently from native non-endemic species (e.g. via the loss of defensive mechanisms), and in such a globally consistent manner, that they cause the strong and consistent pattern we find.

Assuming, then, that percent endemism reflects per-species speciation rate reasonably well, the strong increase in percent endemism with elevation is contrary to predictions derived from the metabolic theory and the biotic interactions ('diversity begets diversity') and area hypotheses. This is consistent with findings by McCain \& Sanders (2010) that the metabolic theory does not explain diversity patterns along elevational gradients. With their elevational ranges varying from about 800 $6000 \mathrm{~m}$, our 50 datasets all represent strong temperature gradients (approximately $5-40{ }^{\circ} \mathrm{C}$ temperature ranges), and both species richness and area of elevational bands tend to vary within each dataset by orders of magnitude (Figs 3 and S2). If those are the main drivers of speciation in our study areas then they should account for more variation in percent endemism than does isolation, but they do not. This widespread increase in percent endemism with elevation and the strong effect attributed to isolation are, however, consistent with an increase in speciation driven by elevational isolation. It is also consistent with the notion of an island biogeography of elevational zones. Thus there is a strong indication that elevation-induced isolation overrides possible effects of temperature, biotic interactions and area on speciation along the elevational gradients investigated here.

Reduction with elevation in species' ability to disperse between elevation zones could help account for the pattern in Fig. 2, and would represent an influence of topography-driven isolation additional to speciation. While the mechanism of topography-driven isolation is invariant with time, 
sufficient time is required for speciation to result from isolation. One reason why few high-latitude mountains contain endemic species is because most have suffered recent massive extinction by glaciation. Note that this lack of endemic species (and also low native plant species richness at high elevations in high latitudes) excludes high latitudes from our analyses, while being consistent with, and expected from, our reasoning.

\section{Topography-driven isolation may drive diversification increasingly towards the tropics}

While, on the basis of our findings, we cannot reject other theories for latitudinal gradients, our findings and reasoning are in line with empirical studies that found stronger coarse-resolution correlations in lower latitudes between species richness and topography than with other potential drivers (e.g. Kreft \& Jetz, 2007). It has also been suggested that speciation associated with tropical mountains may have fuelled today's tropical diversity (Hughes \& Eastwood, 2006; Thomas et al., 2008; Fjeldså et al., 2012); phylogenetic research provides qualified support (Särkinen et al., 2012), and there are examples of the ancestors of tropical lowland lineages being montane (e.g. Elias et al., 2009). Our findings are consistent with this notion, and imply that topography-driven isolation is an important mechanism increasing speciation rate towards the equator.

Systematic global variation in the isolating influence of elevation was proposed by Janzen (1967; see also Osborne, 2012), who argued that smaller climatic niches of tropical taxa (which do not have to tolerate much seasonal variation in temperature) mean much stronger dispersal limitation caused by topography in warmer, less seasonal climates than in higher latitudes. Despite the title of Janzen's paper, this reasoning applies to crossing lower elevations (e.g. valleys) as well as higher ones (e.g. mountain passes), though the magnitude of the effect may not scale linearly (Ghalambor et al., 2006). In addition to the direct effect of smaller niches, the reduced seasonality at lower latitudes may also select for lower dispersal ability (Jocque et al., 2010).

In addition to Janzen's suggested increase in effective elevation at low latitudes, the 'glacial buzzsaw' tends to decrease absolute elevations at high latitudes (Egholm et al., 2009; Fig. 4). This is because, during periods of repeated glaciations of poleward regions (as currently, in the Quaternary), higher-latitude mountains are particularly eroded by glaciers and ice sheets. We suggest that these latitudinal trends in both absolute and effective elevational ranges combine to cause much higher probabilities of isolation, and thus promote higher speciation rates per unit area, in mountainous areas at lower latitudes. The slope of the relationship between percent endemism and elevation may or may not change with latitude, but the chance of isolation by topography at any elevation is much greater at lower latitudes. From this, we suggest that the latitudinal diversity gradient may result in part from mountains being much higher in bioclimatic and ecological terms at lower latitudes, working as speciation pumps that can enhance species richness also in surrounding lowlands (Gillespie \& Roderick, 2014).

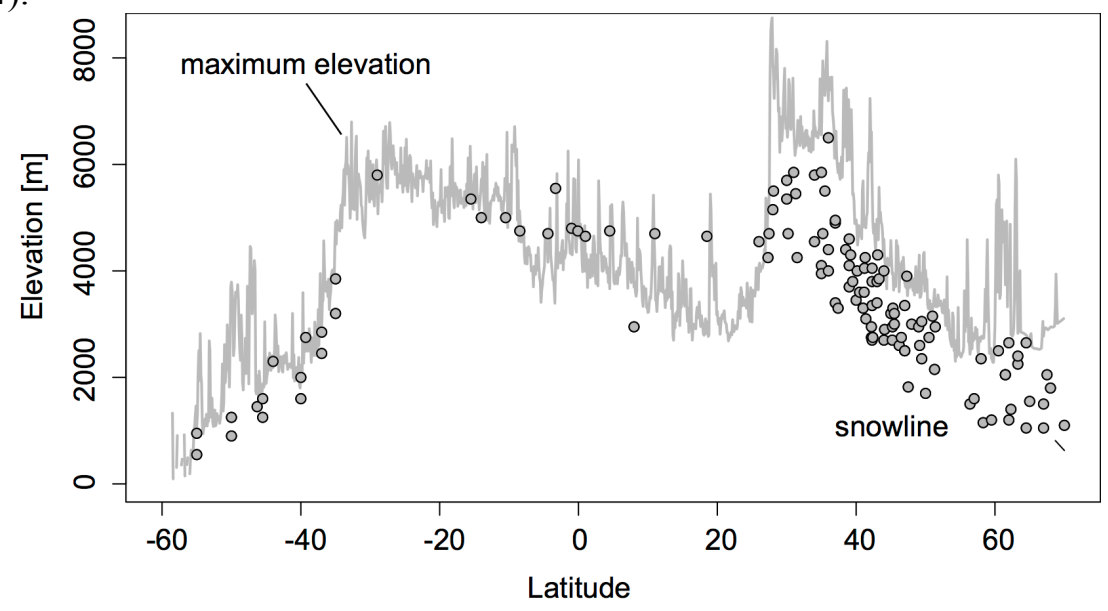

Figure 4: The elevational range where plants grow is limited by mountain elevation and the permanent snowline. Both increase from high latitudes towards the subtropics and tropics. This and the possibility of species having smaller ecological niches towards the tropics increases the chance of topography-driven isolation and thus speciation towards the tropics (Figure 5). The grey line displays the highest elevation value per latitudinal band, derived from a $1 \mathrm{~km}^{2}$ resolution digital elevation model. The points show the permanent snowline, based on data extracted from Hermes (1955). 
Temporal dynamics in topography-driven isolation

Changing environmental conditions, such as during Milankovitch glacial-interglacial cycles, and the associated range shifts of species, may repeatedly divide and merge populations at varying elevations, again working as speciation pumps (Fig. 5; Qian \& Ricklefs, 2000; Cadena et al., 2012; Gillespie \& Roderick, 2014) similar to those reported for oceanic island archipelagos (Ricklefs \& Bermingham, 2007). This process will increase allopatric speciation by repeated isolation as well as hybridization and polyploidy in the phases of remixing of related taxa. While Milankovitch glacial-interglacial cycles may thus hinder speciation in areas with low topographical complexity (Dynesius \& Jansson 2000), they may boost diversification in mountain ranges, where isolation is likely and the extinction risk low because of low climate-change velocity (Sandel et al., 2011; Fjeldså et al., 2012). Topography-enhanced speciation by repeated isolation has previously been proposed as a mechanism to increase tropical biodiversity (Nores, 1999; Haffer \& Prance, 2001; Elias et al., 2009), but in rather specific ways, such that its relevance for the latitudinal diversity gradient may have been underplayed.

On much longer timescales, strong latitudinal diversity gradients comparable to what we observe today may be restricted to periods of the Phanerozoic characterized by 'icehouse' climatic regimes (Mannion et al., 2014). Among other reasons, the absence of the 'glacial buzzsaw' during much of Earth's history would reduce the latitudinal gradient in topography-driven isolation, especially when combined with shallower latitudinal gradients of temperature and seasonality. Thus, times with weakened latitudinal diversity gradients during Earth history may also have been times in which latitudinal trends in topography-driven isolation were much weaker.

a)
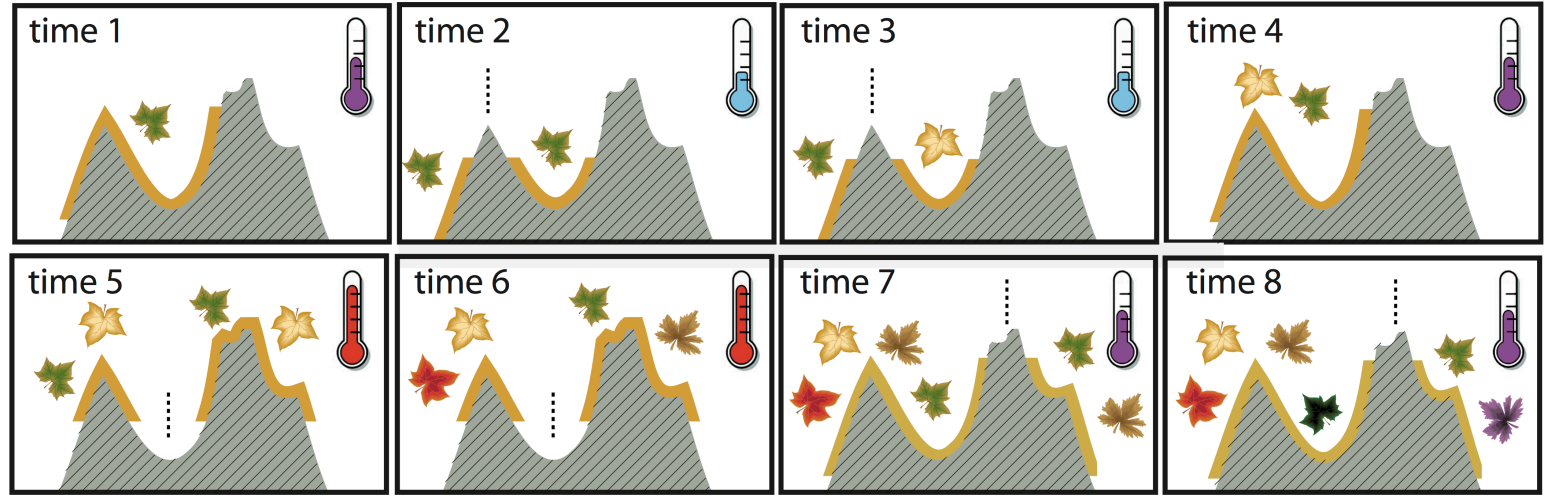

b)

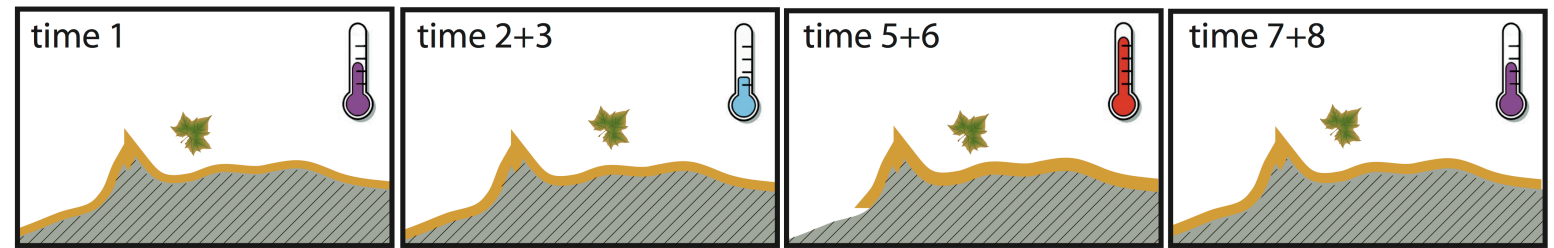

Figure 5: (a) The isolating effect of mountain topography may act as a speciation pump in the presence of climatic fluctuations while (b) landscapes with less variable topography may lack this mode of speciation. The figure is a simplified conceptualisation, the coloured thermometers illustrating climatic changes: red representing warm periods, pale blue for cold periods and dark blue for intermediate temperatures. Thick lines on top of the landscape cross-sections show the distributional range of the clade at each time-point. Changes in leaves (colour and form) indicate divergence (incipient/actual speciation). Speciation may be the result of isolated evolution of lineages (isolation barriers indicated by dashed lines), but also of hybridization and polyploidy when differentiated taxa merge after isolation (not shown but also enhanced by topography). Note that isolation in mountain ranges may occur in valleys or mountain peaks. For simplicity, the illustration assumes (i) that each isolation event is long enough to cause speciation, and (ii) that there is no niche shift or adaptive radiation.

\section{Nature conservation implications}

The globally consistent increase in percent endemism with elevation has important natureconservation implications. High-elevation ecosystems consistently harbour disproportionally high ratios of unique species in relatively small areas, and many are ideal for nature conservation because 
they are not well suited to other land uses (not least on islands, where tourism tends to be based in the lowlands; Sandel \& Svenning, 2013). However, high-elevation endemic species may be adversely affected by climate change, particularly those whose climatic envelopes are set to disappear (Elsen \& Tingler, 2015, Harter et al., 2015). Even so, if elevation drives speciation, future speciation may be maximised by conserving mountainous areas, especially at lower latitudes.

\section{Conclusion}

We suggest that an increase in speciation caused by the isolating effect of topography may significantly contribute to an explanation of latitudinal gradients of beta and gamma diversity, and to variations in those gradients with geological time. This importance of isolation for speciation is consistent with the increase in percent endemism with elevation that we find on high islands and continental mountains around the world.

\section{Acknowledgements}

We thank Thomas Gillespie, David Currie and two anonymous referees for their constructive criticism of an earlier version of this paper. Brody Sandel was very supportive when handling the spatial data. M.J.S. was supported by the Danish Carlsbergfondet Project Number CF14-0148. H.J.B.B. compiled several of the datasets with support from the University of Bergen's Meltzer Fund. M.C.D. and M.M.R. were funded by FCT project: PTDC/BIA-BIC/4113/2012; P.B., P.C., R.E. and R.G. were funded by projects DRCT- M2.1.2/I/027/2011 and DRCT- M2.1.2/I/005/2011.

\section{References}

Allen, A.P. \& Gillooly, J.F. (2006) Assessing latitudinal gradients in speciation rates and biodiversity at the global scale. Ecology Letters, 9, 947-954.

Borges, P.A.V., Gabriel, R., Arroz, A., Costa, A., Cunha, R., Silva, L., Mendonça, E., Martins, A.F., Reis, F. \& Cardoso, P. (2010) The Azorean Biodiversity Portal: an internet database for regional biodiversity outreach. Systematics and Biodiversity, 8, 423-434.

Brown, J.H. (2014) Why are there so many species in the tropics? Journal of Biogeography, 41, 8-22.

Cadena, C.D., Kozak, K.H., Gomez, J.P., Parra, J.L., McCain, C.M., Bowie, R.C.K., Carnaval, A.C., Moritz, C., Rahbek, C., Roberts, T.E., Sanders, N.J., Schneider, C.J., VanDerWal, J., Zamudio, K.R. \& Graham, C.H. (2012) Latitude, elevational climatic zonation and speciation in New World vertebrates. Proceedings of the Royal Society B, 279, 194-201.

Coyne, J.A. \& Orr, H.A. (2004) Speciation. Sinauer Associates, Sunderland, MA. 545 pp.

Cronk, Q.C.B. (1997). Islands: stability, diversity, conservation. Biodiversity and Conservation, 6, 477-493

Egholm, N.S.B., Pedersen, V.K. \& Lesemann, J.E. (2009) Glacial effects limiting mountain height. Nature, 460, 884-887.

Elias, M., Joron, M., Willmott, K., Silva-Brandao, K.L., Kaiser, V., Arias, C.F., Gomez Piñerez, L.M., Uribe, S., Brower, A.V., Freitas, A.V. \& Jiggins, C.D. (2009). Out of the Andes: patterns of diversification in clearwing butterflies. Molecular Ecology, 18, 1716-1729.

Elsen, P.M. \& Tingler, R.W. (2015) Global mountain topography and the fate of montane species under climate change. Nature Climate Change, 5, 772-776.

Emerson, B.C. \& Kolm, N. (2005) Species diversity can drive speciation. Nature, 434, 1015-1017.

Fjeldså, J., Bowie, R.C.K. \& Rahbek, C. (2012) The role of mountain ranges in the diversification of birds. Annual Review of Ecology and Systematics, 43, 249-265.

Ghalambor, C.K., Huey, R.B., Martin, P.R., Tewksbury, J.T. \& Wang, G. (2006) Are mountain passes higher in the tropics? Janzen's hypothesis revisited. Integrative and Comparative Biology, 46, 517.

Gillespie, R.G. \& Roderick, G.K. (2014) Geology and climate drive diversification. Nature, 509, 297- 
298.

Gillooly, J.F., Allen, A.P., Savage, V.-M. \& West, G.B. (2004) Towards a metabolic theory of ecology. Ecology, 85, 1771-1789.

Haffer, J. \& Prance, G.T. (2001) Climatic forcing of evolution in Amazonia during the Cenozoic: on the refuge theory of biotic differentiation. Amazoniana, 16, 579-605.

Harter, D.E.V., Irl, S.D.H., Seo, B., Steinbauer, M.J., Gillespie, R., Triantis, K.A.., FernándezPalacios, J.M. \& Beierkuhnlein, C. (2015) Impact of global climate change on the floras of oceanic islands - Projections, implications and current knowledge. Perspectives in Plant Ecology, Evolution and Systematics, 17, 160-183.

Hermes, H. (1955). Die Lage der oberen Waldgrenze in den Gebirgen der Erde und ihr Abstand zur Schneegrenze. Kölner Geographische Abhandlungen, 277pp.

Hughes, C. \& Eastwood, R. (2006) Island radiation on a continental scale: Exceptional rates of plant diversification after uplift of the Andes. Proceedings of the Royal Society B, 103, 10334-10339.

Humboldt, A. \& Bonpland, A. (1807) Le voyage aux régions equinoxiales du Nouveau Continent, fait en 1799-1804, Paris.

Hutter, C.R., Guayasamin, J.M. \& Wiens, J.J. (2013) Explaining Andean megadiversity: the evolutionary and ecological causes of glassfrog elevational richness patterns. Ecology Letters, 16, 1135-1144.

Irl, S.D.H., Harter, D.E.V., Steinbauer, M.J., Gallego Puyol, D., Fernández-Palacios, J.M., Jentsch, A., Beierkuhnlein, C. (2015) Climate vs. topography - spatial patterns of plant species diversity and endemism on a high-elevation island. Journal of Ecology, doi: 10.1111/1365-2745.12463

Janzen, D.H. (1967) Why mountain passes are higher in the tropics. The American Naturalist, 101, $233-249$.

Jocque, M., Field, R., Brendonck, L. \& de Meester, L. (2010) Climatic control of dispersal-ecological specialization trade-offs: a metacommunity process at the heart of the latitudinal diversity gradient? Global Ecology and Biogeography, 19, 244-252.

Jump, A.S., Huang, T.-J. \& Chou, C.-H. (2012) Rapid altitudinal migration of mountain plants in Taiwan and its implications for high altitude biodiversity. Ecography, 35, 204-210.

Kessler, M. (2002) The elevational gradient of Andean plant endemism: varying influences of taxonspecific traits and topography at different taxonomic levels. Journal of Biogeography, 29, 11591165.

Kisel, Y. \& Barraclough, T.G. (2010) Speciation has a spatial scale that depends on levels of gene flow. The American Naturalist, 175, 316-334.

Knope, M.L., Morden, C.W., Funk, V.A. \& Fukami, T. (2012) Area and the rapid radiation of Hawaiian Bidens (Asteraceae). Journal of Biogeography, 39, 1206-1216.

Kreft, H. \& Jetz, W. (2007) Global patterns and determinants of vascular plant diversity. Proceedings of the National Academy of Sciences, 104, 5925-5930.

Kreft, H., Jetz, W., Mutke, J., Kier, G. \& Barthlott, W. (2008) Global diversity of island floras from a macroecological perspective. Ecology Letters, 11, 116-127.

Losos, J.B. \& Schluter, D. (2000) Analysis of an evolutionary species-area relationship. Nature, 408, $847-850$.

Mallet-Rodrigues, F., Parrini, R., Pimentel, L.M.S. \& Bessa, R. (2010) Altitudinal distribution of birds in a mountainous region in southeastern Brazil. Zoologia, 27, 503-522.

Mannion, P.D., Upchurch, P., Benson, R.B. \& Goswami, A. (2014) The latitudinal biodiversity gradient through deep time. Trends in Ecology and Evolution, 29, 42-50.

Mayr, E., \& Diamond, J.M. (1976). Birds on islands in the sky: origin of the montane avifauna of 
northern Melanesia. Proceedings of the National Academy of Sciences, 73, 1765-1769.

McCain, C.M. (2005) Elevational gradients in diversity of small mammals. Ecology, 86, 366-372.

McCain, C.M. \& Sanders, N.J. (2010) Metabolic theory and elevational diversity of vertebrate ectotherms. Ecology, 91, 601-609.

Merckx, V.S.F.T., Hendriks, K.P., Beentjes, K.K., Mennes, C.B., Becking, L.E., Peijnenburg, K.T.C.A., Afendy, A., Arumugam, N., de Boer, H., Biun, A., Buang, M.M., Chen, P-P., Chung, A.Y.C., Dow, R., Feijen, F.A.A., Feijen, H., Soest, C.F., Geml, J., Geurts, R., Gravendeel, B., Hovenkamp, P., Imbun, P., Ipor, I., Janssens, S.B., Jocque, M., Kappes, H., Khoo, E., Koomen, P., Lens, F., Majapun, R.J., Morgado, L.N., Neupane, S., Nieser, N., Pereira, J.T., Rahman, H., Sabran, S., Sawang, A., Schwallier, R.M., Shim, P.-S., Smit, H., Sol, N., Spait, M., Stech, M., Stokvis, F., Sugau, J.B., Suleiman, M., Sumail, S., Thomas, D.C., van Tol, J., Tuh, F.Y.Y., Yahya, B.E., Nais, J., Repin, R., Lakim, M. \& Schilthuizen, M. (2015) Evolution of endemism on a young tropical mountain. Nature, 524, 347-350.

Mittelbach, G.G., Schemske, D.W., Cornell, H.V., Allen, A.P., Brown, J.M., Bush, M.B., Harrison, S.P., Hurlbert, A.H., Knowlton, N., Lessios, H.A., McCain, C.M., McCune, A.R., McDade, L.A., McPeek, M.A., Near, T.J., Price, T.D., Ricklefs, R.E., Roy, K., Sax, D.F., Schluter, D., Sobel, J.M. \& Turelli, M. (2007) Evolution and the latitudinal diversity gradient: speciation, extinction and biogeography. Ecology Letters, 10, 315-331.

Nogué, S., Rull, V. \& Vegas-Vilarrúbia, T. (2013) Elevational gradients in the neotropical table mountains: patterns of endemism and implications for conservation. Diversity and Distribution, 19, 676-687.

Nores, M. (1999) An alternative hypothesis for the origin of Amazonian bird diversity. Journal of Biogeography, 26, 475-485.

Osborne, P.L. (2012) Tropical Ecosystems and Ecological Concepts. 2nd edition, Cambridge University Press, Cambridge.

Qian, H. \& Ricklefs, R.E. (2000) Large-scale processes and the Asian bias in species diversity of temperate plants. Nature, 407, 180-182.

Rahbek, C. (1995) The elevational gradient of species richness: a uniform pattern? Ecography, 18, 200-205.

Rohde, K. (1992) Latitudinal gradients in species diversity: the search for the primary cause. Oikos, 65, 514-527.

Ricklefs, R.E. \& Bermingham, E. (2007) The causes of evolutionary radiations in archipelagos: Passerine birds in the Lesser Antilles. The American Naturalist, 169, 285-297.

Salerno, P.E., Ron, S.R., Señaris, C., Rojas-Runjaic, F.J.M., Noonan, B.P. \& Cannatella D.C. (2012) Ancient Tepui summits harbour young rather than old lineages of endemic frogs. Evolution, 66, 3000-3013.

Sandel, B., Arge, L., Dalsgaard, B., Davies, R.G., Gaston, K.J., Sutherland, W.J. \& Svenning, J.-C. (2011). The Influence of Late Quaternary Climate-Change Velocity on Species Endemism. Science, 334, 660-664.

Sandel, B. \& Svenning, J.-C. (2013). Human impacts drive a global topographic signature in tree cover. Nature Communications, 4, 2474.

Särkinen, T., Pennington, R.T., Lavin, M., Simon, M.F. \& Hughes, C.E. (2012) Evolutionary islands in the Andes: persistence and isolation explain high endemism in Andean dry tropical forests. Journal of Biogeography, 39, 884-900.

Steinbauer, M.J., Otto, R., Naranjo-Cigala, A., Beierkuhnlein, C. \& Fernandez-Palacios, J.M. (2012) Increase of island endemism with altitude - speciation processes on oceanic islands. Ecography, 35, 23-32.

Steinbauer, M.J., Irl, S.D.H. \& Beierkuhnlein, C. (2013) Elevation-driven ecological isolation 
promotes diversification on Mediterranean islands, Acta Oecologica, 47, 52-56.

Stuessy, T.F., Jakubowsky, G., Gómez, R.S., Pfosser, M., Schlüter, P.M., Fer, T., Sun, B.Y. \& Kato, H. (2006) Anagenetic evolution in island plants. Journal of Biogeography, 33, 1259-1265.

Thomas, G.H., Orme, C.D.L., Davies, R.G., Olson, V.A., Bennett, P.M., Gaston, K.J., Owens, I.P.F. \& Blackburn, T.M. (2008) Regional variation in the historical components of global avian species richness. Global Ecology and Biogeography, 17, 340-351.

Van Valen, L. (1973) A new evolutionary law. Evolutionary Theory, 1, 1-30.

Vetaas, O.R. \& Grytnes, J.A. (2002) Distribution of vascular plant species richness and endemic richness along the Himalayan elevation gradient in Nepal. Global Ecology and Biogeography, 11, 291-301.

Wallace, A.R. (1880) Island Life: Or, The Phenomena and Causes of Insular Faunas and Floras. Macmillan \& Co., London.

Weigelt, P. \& Kreft, H. (2013) Quantifying island isolation - insights from global patterns of insular plant species richness. Ecography, 36, 417-429.

Whittaker, R.J. \& Fernández-Palacios, J.M. (2007) Island Biogeography: Ecology, Evolution, and Conservation. Second Edition. Oxford University Press, Oxford.

Whittaker, R.J., Willis, K.J. \& Field, R. (2001) Scale and species richness: towards a general, hierarchical theory of species diversity. Journal of Biogeography, 28, 453-470.

Winkworth, R.C., Wagstaff, S.J., Glenny, D. \& Lockhart, P.J. (2004) Evolution of the New Zealand mountain flora: Origins, diversification and dispersal. Organisms Diversity \& Evolution. 5, 237247.

Yule, G.U. (1924) A mathematical theory of evolution, based on the conclusions of Dr J. C. Willis. Philosophical Transactions of the Royal Society B, 213, 21-87.

\section{Biosketches \& author contributions}

Manuel Steinbauer`s research interest is the quantification and understanding of causal drivers behind the dynamics and geography of biota. Manuel Steinbauer is thus investigating biogeographic patterns with particular focus on scale-dependent patterns/processes, theoretical ecology, dispersal and isolated systems like island or mountains.

Richard Field's main interests are in biodiversity patterns, conservation biogeography (particularly with reference to tropical rainforests) and island biogeography.

Author contributions: M.J.S. had the original idea and designed the study with R.F. M.J.S. and R.F. led the writing. M.J.S. J.A.G., P.T., C.A.P., F.A., H.J.B.B. P.A.V.B, P.C., C.H.C., M.D.S., M.C.D., R.B.E., R.G., J.G., T.J.H., D.J., A.S.J., J.P., M.M.R., D.S., T.S. and O.R.V. provided data. M.J.S. performed the analyses and designed the figure. All authors discussed the approach, implementation and results and contributed to the manuscript. C.B. supervised the project. 